\title{
Bilateral Pheochromocytoma Associated with Paraganglioma and Papillary Thyroid Carcinoma: Report of an Unusual Case
}

\author{
JeOng Hoon YANG, Sung Jin BAE, SANGHUi PARK*, Hyun-Kyung PARK**, Hye SEUng JUNG, \\ JAE HoOn CHUNG, Yong-Ki MIN, MYUnG-SHIK LEE, KWANG-Won KIM AND MOON-KYU LEE \\ Department of Medicine, Samsung Medical Center, Sungkyunkwan University School of Medicine, Seoul 135-710, Korea \\ *Department of Pathology, Samsung Medical Center, Sungkyunkwan University School of Medicine, Seoul 135-710, Korea \\ **Department of Laboratory Medicine, Samsung Medical Center, Sungkyunkwan University School of Medicine, Seoul 135-710, Korea
}

\begin{abstract}
A 42-year old woman presented with headache, palpitation and facial flushing. Ultrasonograms and computed tomograms revealed tumors in both of the adrenal glands, anterior aspect of the inferior vena cava, and the right lobe of the thyroid gland. Fine needle aspiration biopsy of the thyroid nodule revealed papillary thyroid carcinoma. Serum calcitonin, CEA, intact PTH and calcium levels were within normal limits. Markedly elevated levels of urinary normetanephrine and vanillylmandelic acid, and the result of ${ }^{131} \mathrm{I}$-metaiodobenzylguanidine ( $\left.{ }^{131} \mathrm{I}-\mathrm{MIBG}\right)$ scintigraphy indicated that both adrenal masses were pheochromocytoma. Bilateral adrenalectomy, paracaval mass removal and total thyroidectomy together with central lymph node dissection were performed. The final pathological diagnosis was bilateral adrenal pheochromocytoma, paraganglioma, papillary thyroid carcinoma and either parathyroid adenoma or hyperplasia. Analysis of the RET proto-oncogene mutation, von Hippel Lindau mutation, succinate dehydrogenase subunit B mutation, and succinate dehydrogenase subunit $\mathrm{D}$ mutation yielded negative results. The relationship of these lesions could not be determined. This is the first report of a combination of bilateral pheochromocytoma, abdominal paraganglioma, papillary thyroid carcinoma and either parathyroid adenoma or hyperplasia without hyperparathyroidism.
\end{abstract}

Key words: Pheochromocytoma, Paraganglioma, Papillary thyroid carcinoma

(Endocrine Journal 54: 227-231, 2007)

PHEOCHROMOCYTOMA and abdominal paragangliomas are catecholamine-producing tumors that arise from paraganglia cells derived from the neural crest. Tumors that arise from cells within the adrenal medulla are defined as pheochromocytoma, whereas tumors arising from the paraganglia located outside the adrenals are called paragangliomas or extra-adrenal pheochromocytomas [1]. While pheochromocytomas occur most commonly as sporadic tumors, approximately $25 \%$ of these tumors are inherited as part of a distinct syndrome such as von Hippel Lindau syndrome (VHL), multiple endocrine neoplasia type 2 (MEN 2), neurofibromatosis type 1 and paraganglioma

Received: April 10, 2006

Accepted: November 22, 2006

Correspondence to: Moon-Kyu LEE, M.D., Department of Medicine, Samsung Medical Center, Sungkyunkwan University School of Medicine, Seoul, Korea syndrome [2]. In MEN 2, there is an association between medullary thyroid carcinoma and pheochromocytoma. However, papillary thyroid carcinoma is rarely associated with pheochromocytoma, and the relationship between pheochromocytoma and papillary thyroid carcinoma remains unclear [3-5].

We present here an unusual case of a patient who had bilateral pheochromocytoma, abdominal paraganglioma, papillary thyroid carcinoma and either parathyroid adenoma or hyperplasia without hyperparathyroidism. The relationship of these lesions is discussed.

\section{Case Report}

A 42-year old woman presented with headache, palpitation, and facial flushing which started seven months prior. She was diagnosed with hypertension one year earlier. The blood pressure was 148/77 
Table 1. Preoperative data on endocrine factors

\begin{tabular}{lll}
\hline \multicolumn{1}{c}{ Laboratory data } & \multicolumn{1}{c}{ Values } & Normal range \\
\hline Plasma & & \\
Free T4 & $1.15 \mathrm{ng} / \mathrm{dl}$ & $0.64-1.72$ \\
TSH & $1.93 \mathrm{uIU} / \mathrm{ml}$ & $0.3-6.5$ \\
CEA & $0.82 \mathrm{ng} / \mathrm{ml}$ & $0-5$ \\
Calcitonin & $3 \mathrm{pg} / \mathrm{ml}$ & $0-13$ \\
Calcium & $8.5 \mathrm{mg} / \mathrm{dl}$ & $8.4-10.2$ \\
Intact PTH & $38.8 \mathrm{pg} / \mathrm{ml}$ & $10-65$ \\
Urine & & \\
VMA & $9.5 \mathrm{mg} / \mathrm{day}$ & $<6.8$ \\
Metanephrine & $234.68 \mu \mathrm{g} /$ day & $45-290$ \\
Normetanephrine & $5435.25 \mu \mathrm{g} /$ day & $82-500$ \\
\hline
\end{tabular}

Abbreviations: TSH; thyroid stimulating hormone, CEA; carcinoembryonic antigen, PTH; parathyroid hormone, VMA; vanillylmandelic acid.

$\mathrm{mmHg}$ and the pulse rate was 97 beats per minute. The physical examination revealed no abnormal findings. There was no specific family history.

Urinary metanephrine, normetanephrine and vanillylmandelic acid (VMA) levels from a 24 hour urine sample were $234.68 \mu \mathrm{g} /$ day ( 45 to $290 \mu \mathrm{g} /$ day), 5435.25 $\mu \mathrm{g} /$ day $(82-500 \mu \mathrm{g} /$ day) and $9.5 \mathrm{mg} /$ day (normal $<6.8$ $\mathrm{mg} /$ day), respectively. Serum calcitonin and CEA levels were within normal limits. Serum intact PTH and calcium levels were also within normal limits (Table 1). Abdominal computed tomography (CT) showed heterogeneously enhanced bilateral adrenal masses (right side size: $4.6 \mathrm{~cm} \times 2.8 \mathrm{~cm}$; left side size: $2.5 \mathrm{~cm}$ $\times 2.1 \mathrm{~cm}$ ) and another $1.6 \mathrm{~cm} \times 1 \mathrm{~cm}$ sized enhancing lesion at the anterior aspect of the inferior vena cava (Fig. 1). ${ }^{131} \mathrm{I}-\mathrm{MIBG}$ scintigraphy demonstrated an increased uptake over the bilateral adrenal masses (Fig. 2). Ultrasonography of the thyroid gland showed an approximately $0.6 \mathrm{~cm}$-sized, irregularly marginated calcified nodule in the right thyroid gland, and this was diagnosed as a papillary thyroid carcinoma by fine needle aspiration and cytology. The patient underwent bilateral adrenalectomy, paracaval mass removal and total thyroidectomy together with central lymph node dissection. Four parathyroids were carefully preserved, but one parathyroid $(4 \mathrm{~mm} \times 3 \mathrm{~mm} \times 3 \mathrm{~mm})$ was incidental and was removed with thyroid. The final pathological diagnosis was bilateral adrenal pheochromocytoma (Fig. 3A), paraganglioma (Fig. 3B), papillary thyroid carcinoma (stage 1, T1N1M0) (Fig. 3C) and either parathyroid adenoma or hyperplasia (Fig. 3D). Immunohistochemically, chromogranin A stain-

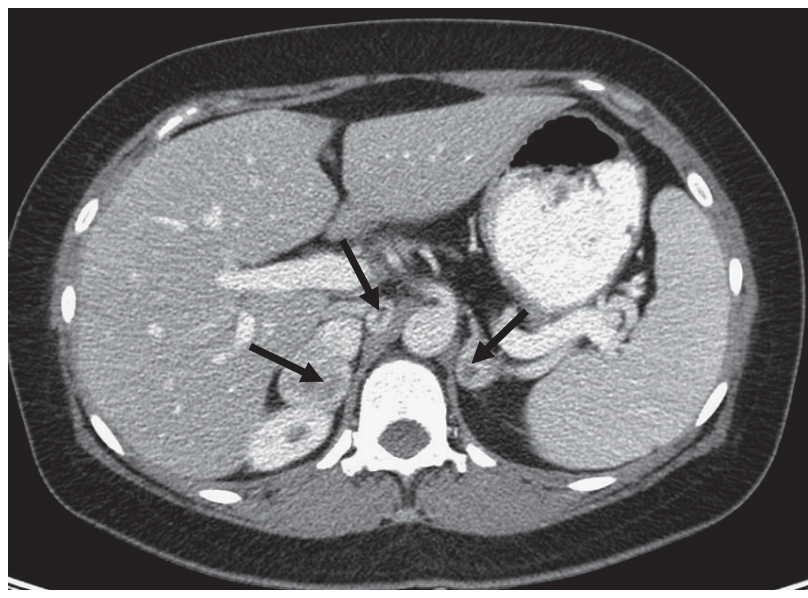

Fig. 1. CT scan after contrast enhancement shows an enhanced mass with a central area compatible with necrosis in the both adrenal glands and the retrocaval space (arrows).
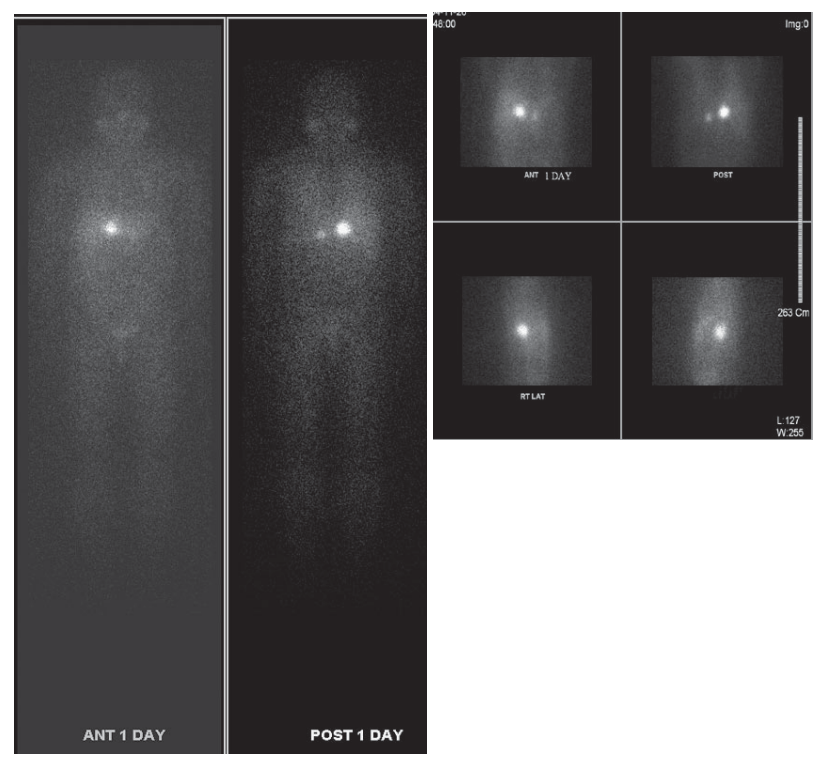

Fig. 2. ${ }^{131} \mathrm{I}-\mathrm{MIBG}$ scan shows increased uptake in the upper abdomen, probably both adrenal glands.

ing as specific marker was positive and Ki67 staining as a marker of recurrence or metastasis was not significantly immunoreactive (Fig. 3E, 3F). Postoperatively, the hypertension and related symptoms were resolved and the level of urinary catecholamine metabolites recovered to their normal values. Two hundred microliters of blood were used for genomic DNA extraction using the Wizard Genomic DNA Purification Kit following the manufacturer's instructions (Promega, Madison, WI). Genomic DNA was also extracted from papillary thyroid carcinoma using the High Pure PCR 


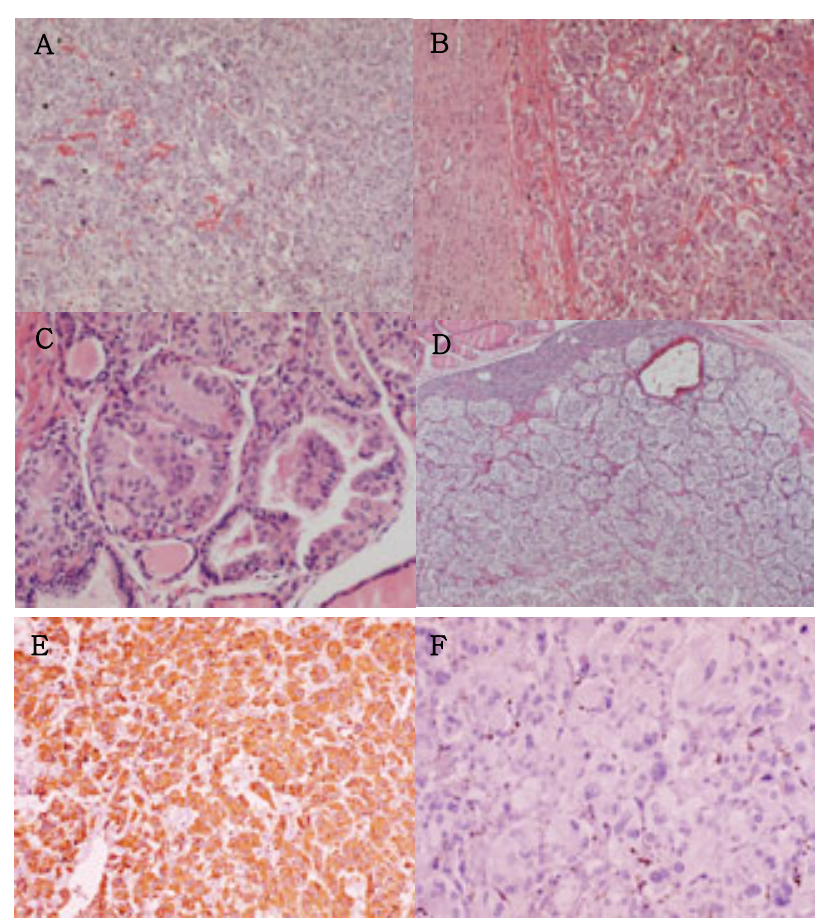

Fig. 3. Microscopic features of pheochromocytoma, paraganglioma, papillary thyroid carcinoma, either parathyroid adenoma or hyperplasia.

A. Microscopic features of pheochromocytoma. Nests of tumor cells are separated by thin connective tissue stroma, containing abundant thin walled blood vessels. The tumor cells have oval nuclei and abundant granular cytoplasm $(\mathrm{H} \& \mathrm{E} \times 100)$.

B. Microscopic features of the paraganglioma (H\&E $\times 100)$.

C. Microscopic features of the thyroid tumor. The sheets of tumor cells constitute well differentiated papillary thyroid carcinoma, containing small tubular glandlike structures. Colloid is present $(\mathrm{H} \& \mathrm{E} \times 200)$.

D. Microscopic features of either parathyroid adenoma or hyperplasia. The tissue is well encapsulated and very cellular; it is composed of variable sized cells with small round hyperchromic nuclei and clear or eosinophilic cytoplasm $(\mathrm{H} \& \mathrm{E} \times 40)$.

E. Immunohistochemistry stain of pheochromocytoma. The chromogranin A stain is positive $(\times 100)$.

F. Immunohistochemistry stain of pheochromocytoma. The Ki67 stain is not significantly immunoreactive $(\times 100)$.

Template Preparation Kit (Roche, GmbH, Germany). The coding exons and their flanking introns of the RET (exon 10,11, 13, 14, 15 and 16), von Hippel Lindau $(V H L)$, succinate dehydrogenase subunit B $(S D H B)$, and succinate dehydrogenase subunit $\mathrm{D}(S D H D)$ genes were amplified using primers designed by the authors (available on request). Direct sequencing was performed with the BigDye Terminator Cycle Sequencing Ready Reaction kit (Applied Biosystems, Foster City, CA) on the ABI 3100 Genetic Analyzer (Applied Biosystems). Analysis of the RET, VHL, SDHB, and $S D H D$ genes yielded no mutation. Furthermore, we also analyzed somatic mutation of the RET, but no mutation was detected.

\section{Discussion}

We have described a case of bilateral pheochromocytoma associated with abdominal paraganglioma, papillary thyroid carcinoma and either parathyroid adenoma or hyperplasia. Generally, patients with bilateral pheochromocytoma are more likely to have a genetic basis for their disease. During the past ten years, it has been recognized that pheochromocytomas are tumors commonly found in patients with VHL, MEN 2 and neurofibromatosis type 1, occurring as a result of germline mutations in $V H L, R E T$ or $N F 1$, respectively [6]. The frequency of germline mutations in these genes was much higher than previously estimated. More recently nuclear genes encoding two mitochondrial complex II subunit proteins, SDHD and $S D H B$, have been associated with the development of familial pheochromocytomas and paragangliomas [7, 8]. Head and neck paraganglioma were statistically more prevalent among $S D H D$ carriers compared with those with $S D H B$ mutations, although intra-abdominal tumors were more prevalent among $S D H B$ mutation carriers [9]. For $S D H B$ mutation carriers, a high rate of distant metastases has been reported, and consistent with the apparently aggressive nature of $S D H B$ dysfunction, some carriers of the mutation were also found to have extraparaganglial malignancies (e.g., renal cell carcinoma and papillary thyroid carcinoma) [9]. But whether these extraparaganglial malignancies are also components of $S D H B$ related disease awaits further confirmation.

The association of thyroid carcinoma in patients with pheochromocytoma is 14 times greater than in the general population. The increased incidence might be due to the fluctuating thyrotropin secretion caused by circulating catecholamines [10-12]. The association of medullary thyroid carcinoma with pheochromocytoma is well known in Sipple's syndrome (MEN 2A) $[3,10-13]$. However, the association between papil- 
lary thyroid carcinoma and adrenal or extraadrenal pheochromocytoma is rare $[3,5,10]$. In 1983, Sato et al. reviewed 526 Japanese cases of pheochromocytoma and reported that three of them were associated with papillary thyroid carcinoma [14]. Pheochromocytomas are capable of producing and secreting a number of peptides such as insulin-like growth factor II [15], hypothalamic-like and pituitary-like hormones [16]. These biological substances might cause the development and growth of papillary thyroid carcinoma [10].

Although the pathological association of thyroid and parathyroid disease is common, the association of both parathyroid adenoma and thyroid cancer is rare [17]. Steiner et al. suggested that association of parathyroid tumors and papillary thyroid carcinoma might occur as in MEN 3 [18]. Ellenberg et al. reported that seven of a series of 93 cases of parathyroid adenoma were associated with adenocarcinoma of the thyroid gland. They speculated that hypercalcemia caused by parathyroid adenoma acted as a goitrogen capable of stimulating the thyroid to develop thyroid carcinoma [19].

Our patient had bilateral pheochromocytoma, abdominal paraganglioma, papillary thyroid carcinoma and either parathyroid adenoma or hyperplasia. But the levels of serum calcium and intact PTH were within normal limits and there was no evidence of medullary thyroid carcinoma, $R E T$ proto-oncogene germline or somatic mutations, and $V H L$ germline mutations. The clinical features of the patient were not compatible with the diagnosis of VHL syndrome or neurofibromatosis type 1 nor was there evidence of $S D H B, S D H D$ germline mutations. Therefore, it is likely that each tumor in this case developed sporadically. This is the first reported case of a combination of bilateral pheochromocytoma, paraganglioma, papillary thyroid carcinoma and either parathyroid adenoma or hyperplasia without hyperparathyroidism. The relationship of these lesions remains unclear in this patient. However, our findings might provide a clue for the existence of an evolving syndrome of multiple endocrine neoplasia.

\section{References}

1. Elder EE, Elder G, Larsson C (2005) Pheochromocytoma and functional paraganglioma syndrome: no longer the 10\% tumor. J Surg Oncol 89: 193-201.

2. Dahia PL (2006) Evolving concepts in pheochromocytoma and paraganglioma. Curr Opin Oncol 18: 1-8.

3. Oishi S, Sasaki M, Sato T, Isogai M (1995) Coexistence of MEN 2A and papillary thyroid carcinoma and a recurrent pheochromocytoma 23 years after surgery: report of a case and a review of the Japanese literature. Jpn J Clin Oncol 25: 153-158.

4. Tseng FY, Chang CC, Peng WJ, Chan KC, Chang SL, Chang TC, Lai MK, Huang SH, Shun CT (1999) A case of extraadrenal pheochromocytoma associated with adrenal cortical nodular hyperplasia and papillary thyroid carcinoma. Endocr J 46: 35-41.

5. Kido Y, Kuwano H, Yano K, Mori M, Kitamura K (1992) Concurrent adrenal pheochromocytoma and papillary adenocarcinoma of the thyroid in a 20 -yearold man. Tumori 78: 59-62.

6. Benn DE, Gimenez-Roqueplo AP, Reilly JR, Bertherat J, Burgess J, Byth K, Croxson M, Dahia PL, Elston M, Gimm O, Henley D, Herman P, Murday V, NiccoliSire P, Pasieka JL, Rohmer V, Tucker K, Jeunemaitre X, Marsh DJ, Plouin PF, Robinson BG (2006) Clinical presentation and penetrance of pheochromocytoma/ paraganglioma syndromes. J Clin Endocrinol Metab 91: 827-836.

7. Baysal BE, Ferrell RE, Willett-Brozick JE, Lawrence
EC, Myssiorek D, Bosch A, van der Mey A, Taschner PE, Rubinstein WS, Myers EN, Richard CW 3rd, Cornelisse CJ, Devilee P, Devlin B (2000) Mutations in SDHD, a mitochondrial complex II gene, in hereditary paraganglioma. Science 287: 848-851.

8. Astuti D, Latif F, Dallol A, Dahia PL, Douglas F, George E, Skoldberg F, Husebye ES, Eng C, Maher ER (2001) Gene mutations in the succinate dehydrogenase subunit SDHB cause susceptibility to familial pheochromocytoma and to familial paraganglioma. $A m J$ Hum Genet 69: 49-54.

9. Neumann HP, Pawlu C, Peczkowska M, Bausch B, McWhinney SR, Muresan M, Buchta M, Franke G, Klisch J, Bley TA, Hoegerle S, Boedeker CC, Opocher G, Schipper J, Januszewicz A, Eng C (2004) Distinct clinical features of paraganglioma syndromes associated with SDHB and SDHD gene mutations. JAMA 292: 943-951.

10. Bone HG 3rd (1990) Diagnosis of the multiglandular endocrine neoplasias. Clin Chem 36: 711-718.

11. Fassbender WJ, Krohn-Grimberghe B, Gortz B, Litzlbauer D, Stracke H, Raue F, Kaiser HE (2000) Multiple endocrine neoplasia (MEN) - an overview and case report - patient with sporadic bilateral pheochromocytoma, hyperparathyroidism and marfanoid habitus. Anticancer Res 20: 4877-4887.

12. Yasuda G, Shionoiri H, Hamada K, Umemura S, Hiroto S, Takasaki I, Kaneko Y (1985) Bilateral 
pheochromocytoma associated with papillary adenocarcinoma of the thyroid gland; report of an unusual case. Endocrinol Jpn 32: 399-404.

13. Sipple JH (1961) The association of pheochromocytoma with carcinoma of the thyroid gland. Am J Med 31: 163-166.

14. Sato T, OS, Iwaoka T, Umeda T (1983) Pheochromocytoma. Nippon Rinsho 41: 879-890.

15. Gelato MC, Vassalotti J (1990) Insulin-like growth factor-II: possible local growth factor in pheochromocytoma. J Clin Endocrinol Metab 71: 1168-1174.

16. Spark RF, Connolly PB, Gluckin DS, White R, Sacks B, Landsberg L (1979) ACTH secretion from a function- ing pheochromocytoma. N Engl J Med 301: 416-418.

17. Meshikhes AW, Butt SA, Al-Saihati BA (2004) Combined parathyroid adenoma and an occult papillary carcinoma. Saudi Med J 25: 1707-1710.

18. Steiner AL, Goodman AD, Powers SR (1968) Study of a kindred with pheochromocytoma, medullary thyroid carcinoma, hyperparathyroidism and Cushing's disease: multiple endocrine neoplasia, type 2. Medicine (Baltimore) 47: 371-409.

19. Ellenberg AH, Goldman L, Gordan GS, Lindsay S (1962) Thyroid carcinoma in patients with hyperparathyroidism. Surgery 51: 708-717. 